\title{
Risk Mitigation Methods for Removal of Pesticide Residues in Tomato for Food Safety
}

\author{
Shashi Vemuri, Cherukuri Sreenivasa Rao, Harinatha Reddy A, S. Swarupa, \\ K.Kavitha V. Anitha
}

All India Network Project on Pesticide Residues Prof. Jayashankar Telangana State Agricultural University Rajendra nagar, Hyderabad, Telangana, India

Sash_3156@yahoo.co.in

\begin{abstract}
The commercial production of highly cultivated and consumed tomato is highly dependent on regular usage of insecticides to protect the crop from insect pests. The increased consumer awareness and legal issues on food safety, with special reference to insecticide residues in foods, led us to attempt for cheap and effective methods for removal of pesticide residues to address the issues of consumer and food safety, as the farmers are not following the Good Agricultural Practices i.e pre-harvest intervals. The most commonly used pesticides such as profenophos, chlorpyriphos, dimethoate, malathion, phosalone, quinalphos, triazophos and $\lambda$-cyhalothrin were sprayed at recommended doses at fruit formation stage, samples were collected at 2 hours after treatment to quantify the deposits. The samples were subjected to various household treatments (tap water wash, lemon water wash, dipping in $2 \%$ salt water for 15 min, dipping in $2 \%$ tamarind water for 10 min, washing with $0.1 \%$ sodium bicarbonate solution, washing with $4 \%$ acetic acid solution, biowash, cooking), each in three replications, and analysed for residues using validated QuEChERS method and GC-ECD, FPD and GC-MS, so as to estimate the \% removal and their effectiveness. Out of all treatments, dipping in $2 \%$ salt solution for 10 minutes is very effective in removing $45 \%, 43 \%, 52 \%, 50 \%, 54 \%, 48 \%$ and $76 \%$ of dimethoate, chlorpyriphos, quinalphos, profenophos, phosalone, $\square$-cyhalothrin and malathion, respectively, and cooking removed insecticides in the range 55-80\%. Dipping fruits and vegetables in 2\% salt solution for 15 minutes is the best household method for removal of pesticide residues, and also the method is effective in reducing the residues below MRL (Maximum Residue Limits).
\end{abstract}

Keywords: Pesticide Residues, Tomato, Food Safety, Risk Mitigation, 2\% salt solution.

\section{INTRODUCTION}

Tomato is the most popular vegetable in India, and state of Andhra Pradesh is third most important growing Tomato producing 1.615 M mt with a share of 12\% (NHB, 2013) during 2012-13. In India, about $13-14 \%$ of the total pesticides used in agriculture are used for fruits and vegetables covering only 3\% of the cropped area (Arora and Singh, 2004). Repeated application of pesticides on vegetables often results in the build up of their residues (Handa, 1992). Surveys carried out in the country indicated that $50-70 \%$ of vegetables are contaminated with insecticide residues (Karanth, 2000). Studies on farm gate monitoring of vegetables carried out in different places revealed contamination mostly with organo phosphorous and synthetic pyrethroids insecticides, indicating clearly the changes in the usage pattern from organo chlorine to other groups of pesticides.

Maximum Residue Limits (MRLs) are set by Codex Alimentarius Commission (CAC) at international level and as on date, MRLs are set for 17 pesticides on tomato, and by Food Safety and Standards Authority of India (FSSAI) of Ministry of Health and Family Welfare, Government of India, as per Food Safety and Standards Act, 2006 (Food Safety and Standards Regulation, 2011) at national level based on the Good Agricultural Practices. The major insect pest of tomato is fruit and shoot borer for which farmers apply insecticides at almost weekly interval, and hence the risk of pesticide residues in foods need to be addressed as per FSSAI (Food Safety and Standards Authority of India) for the protection of consumer health and interests. In this context, household risk mitigation methods for removal of pesticide residues in tomato are to be recommended based on the scientific evaluation, as the food habits are changing enormously. 


\section{Materials AND Methods}

\section{Field Trial Protocol}

A supervised field trial was conducted during Rabi 2012-13 in order to study the effect of house hold processing methods in the removal of certain pesticides in tomato resulting from spray application of most commonly used insecticides viz., Profenophos 50EC@ 2ml/lit, Chlorpyrifos 20EC @ 2ml/lit, Dimethoate 30EC @ 4ml/lit, Malathion 50EC @ 3ml/lit, Phosalone 35EC@3ml/lit, Quinalphos 25EC@ 2ml/lit, Triazophos 40EC @ 2.5ml/lit, Lamda cyhalothrin 5EC@ 0.6ml/lit. Single spray was given at fruiting stage and tomato fruit samples were collected after 2 hours and brought to the laboratory for further analysis. The field trail was conducted in randomized block design, and all the treatments were replicated thrice.

\section{Residue Analysis Method Validation}

Prior to sample collection, AOAC official method 2007.01 (QuEChERS) for residue analysis of dimethoate, profenophos, chlorpyrifos, malathion, phosalone, quinalphos, triazophos, $\lambda$-cyhalothrin was validated by fortifying control samples at $0.50 \mathrm{mg} / \mathrm{kg}$ level, and the results indicated that the method was good as the recovery per cent was 97, 119, 96, 103, 114, 93, 99 and 97, respectively, and hence the method is used for analysis. The details of the method are as follows

- Tomato samples were homogenized with robot coupe blixer (high volume homogenizer). $15 \pm 0.1 \mathrm{~g}$ sample was taken in $50 \mathrm{ml}$ centrifuge tube, and $30 \pm 0.1 \mathrm{ml}$ acetonitrile was added.

- The sample was homogenized (low volume homogenizer) at 14000-15000 rpm for 2-3 min using Heidolph silent crusher, then added with $3 \pm 0.1 \mathrm{~g}$ sodium chloride, mixed by shaking gently followed by centrifugation for $3 \mathrm{~min}$ at $2500-3000 \mathrm{rpm}$ to separate the organic layer.

- The top organic layer of about $16 \mathrm{ml}$ was taken into the $50 \mathrm{ml}$ centrifuge tube and added with $9 \pm 0.1 \mathrm{~g}$ anhydrous sodium sulphate to remove the moisture content.

- $8 \mathrm{ml}$ of extract was taken in to $15 \mathrm{ml}$ tube, containing $0.4 \pm 0.01 \mathrm{gr}$ PSA sorbent (for dispersive solid phase d-SPE cleanup) and 1.2 \pm 0.01 gr anhydrous magnesium sulphate. The sample tube was vortexed for $30 \mathrm{sec}$ then followed by centrifugation for $5 \mathrm{~min}$ at $2500-3000 \mathrm{rpm}$.

- The extract of about $2 \mathrm{ml}$ was transferred into test tubes and evaporated to dryness using turbovap with nitrogen gas and reconstituted with $1 \mathrm{ml} n$-Hexane for GC analysis with ECD and FPD detector. The GC column end at detector was fitted with Universal "Y" splitter for simultaneous analysis of insecticides on both detectors for confirmatory analysis. All pesticides could be detected and quantified on both ECD and FPD, except for triazophos and $\lambda$-cyhalothrin which could be detected only on ECD and FPD, respectively. The samples were also analysed on GC-MS/MS (triple quadrupole) for confirmatory analysis.

\section{Decontamination Methods}

After spray of pesticide, about $15 \mathrm{kgs}$ of tomato fruits were collected randomly in polythene bags from each plot to avoid cross contamination. Each lot from treatment plot was divided in to 8 sub-lots, where one lot was analysed for initial deposits, and remaining lots were subjected to various rick mitigation methods prior to analysis. All samples were replicated thrice. The decontamination methods used in the study are presented in Table 1.

Table1. Decontamination methods used in the study

\begin{tabular}{|c|c|}
\hline $\mathrm{T} 1$ & Dipping in tap water for 10 minutes and washing under tap water for $30 \mathrm{sec}$ \\
\hline $\mathrm{T} 2$ & $\begin{array}{c}\text { Dipping in } 2 \% \text { salt solution for } 10 \text { min: } 80 \text { grams of table salt is added to } 4 \text { lts of water, and } 1 \mathrm{~kg} \text { tomato } \\
\text { sample dipped in salt water for } 10 \mathrm{~min} \text {. }\end{array}$ \\
\hline T3 & $\begin{array}{c}\text { Dipping in 2\% tamarind Solution for } 10 \mathrm{~min}: 80 \text { grams of tamarind is added to } 4 \text { lts of water, and } 1 \mathrm{~kg} \\
\text { tomato sample dipped in salt water for } 10 \mathrm{~min} .\end{array}$ \\
\hline $\mathrm{T} 4$ & $\begin{array}{l}\text { Dipping in Lemon water (1Lemon/1lit) for 10min: Juice of } 4 \text { lemons is added to } 4 \text { lts of water, and } 1 \mathrm{~kg} \\
\text { tomato samples is dipped in lemon water for } 10 \mathrm{~min} \text {. }\end{array}$ \\
\hline T5 & $\begin{array}{l}\text { Dipping in } 0.1 \% \text { Sodium Bicarbonate solution for 10min: } 4 \text { grams of sodium bicarbonate is added to } 4 \text { lts of } \\
\text { water; } 1 \mathrm{~kg} \text { tomato sample is dipped in solution for } 10 \mathrm{~min} \text {. }\end{array}$ \\
\hline T6 & $\begin{array}{c}\text { Dipping in 4\% Acetic acid solution for } 1 \mathrm{~min}: 160 \mathrm{ml} \text { of acetic acid is added to } 4 \text { lts of water; } 1 \mathrm{~kg} \text { tomato } \\
\text { samples dipped in the solution for } 10 \mathrm{~min} .\end{array}$ \\
\hline $\mathrm{T} 7$ & $\begin{array}{l}\text { Dipping in Formula } 1 \text { (4\% Acetic acid+ } 0.1 \% \text { NAHCO3+ } 1 \text { Lemon (1Lemon/1lit): } 160 \mathrm{ml} \text { of acetic acid, } 4 \\
\text { gms of sodium bicarbonate, lemon juice of } 4 \text { lemons added to } 4 \text { lts of water; } 1 \mathrm{~kg} \text { tomato samples dipping in } \\
\text { solution for } 10 \mathrm{~min} .\end{array}$ \\
\hline T8 & Cooking in Pressure cooker: $1 \mathrm{~kg}$ tomato sample is cooked in pressure cooker for $5 \mathrm{~min}$. \\
\hline T9 & $\begin{array}{c}\text { Washing with Bio wash keep it for 10min: } 8 \mathrm{ml} \text { of commercial formula Biowash is added to } 4 \text { lts of water } \\
\text { and } 1 \mathrm{~kg} \text { tomato samples is dipped in solution for } 10 \mathrm{~min} \text {. }\end{array}$ \\
\hline
\end{tabular}


After treatment, tomato samples were taken out and air dried for $5 \mathrm{~min}$ and analysed for residues after treatment as per validated AOAC official method 2007.01 (QuEChERS).

GC operating parameters for Profenophos, Chlorpyrifos, Dimethoate, Malathion, Phosalone, Quinalphos, Triazophos, Lamda cyhalothrin analysis

\begin{tabular}{|c|c|c|c|}
\hline Gas Chromatograph & \multicolumn{3}{|c|}{ SHIMADZU - 2010} \\
\hline Detector & \multicolumn{3}{|c|}{ Electron Capture Detector and Flame photometric detecteor } \\
\hline Column & \multicolumn{3}{|c|}{$\begin{array}{c}\text { GC Capillary Column, MR 1 } \\
30 \mathrm{mts}, 0.25 \mathrm{~mm} \text { ID, } 0.25 \mathrm{~mm} \text { Film Thickness }\end{array}$} \\
\hline Injector Temp & \multicolumn{3}{|c|}{$260^{\circ} \mathrm{C}$} \\
\hline Injector Status & \multicolumn{3}{|c|}{ Split 10} \\
\hline Carrier Gas & \multicolumn{3}{|c|}{ Nitrogen (Prox Air) } \\
\hline Carrier Gas Flow & \multicolumn{3}{|c|}{$1.0 \mathrm{ml} / \mathrm{min}$} \\
\hline Column Oven & \multicolumn{3}{|c|}{$\begin{array}{l}150{ }^{\circ} \mathrm{C}-5 \mathrm{~min} \text { hold up to } 200^{\circ} \mathrm{C} \text { and then } 5 \mathrm{~min} \text { hold and increase } \\
2^{\circ} \mathrm{C} / \mathrm{min} \text { - up to } 280^{\circ} \mathrm{Chold} \text { it for } 10 \mathrm{~min} \text {. TOTAL } 60.00 \mathrm{~min}\end{array}$} \\
\hline ECD Temp & \multicolumn{3}{|c|}{$300^{\circ} \mathrm{C}$} \\
\hline Makeup Flow & \multicolumn{3}{|c|}{$25 \mathrm{ml} / \mathrm{min}$} \\
\hline Retention Time (min) & \begin{tabular}{l} 
Dimethoate \\
Malathion \\
Chlorpyrifos \\
Quinalphos \\
Profenophos \\
Phosalone \\
Triazophos \\
\multicolumn{1}{c}{ Lamda cyhalothrin }
\end{tabular} & $\begin{array}{l}\text { ECD } \\
-15.3 \mathrm{~min} \\
21.8 \mathrm{~min} \\
-22.2 \mathrm{~min} \\
26.7 \mathrm{~min} \\
-30.7 \mathrm{~min} \\
-47.7 \mathrm{~min} \\
-\quad- \\
-48.4 \mathrm{~min}\end{array}$ & $\begin{array}{c}\text { FPD } \\
15.19 \mathrm{~min} \\
21.73 \mathrm{~min} \\
22.11 \mathrm{~min} \\
26.58 \mathrm{~min} \\
30.60 \mathrm{~min} \\
34.43 \mathrm{~min} \\
37.40 \mathrm{~min} \\
-\end{array}$ \\
\hline
\end{tabular}

\section{Results of Fortification and Recovery Studies in Tomato}

The control / Tomato samples were fortified at $0.50 \mathrm{mg} / \mathrm{kg}$ levels adding required quantity of Profenophos, Chlorpyrifos, Dimethoate, Malathion, Phosalone, Quinalphos, Triazophos, Lamda cyhalothrin standards and replicated thrice.The following are the recoveries of Profenophos, Chlorpyrifos, Dimethoate, Malathion, Phosalone, Quinalphos, Triazophos, Lamda cyhalothrin at three different fortification levels.

Recoveries of Profenophos, Chlorpyrifos, Dimethoate, at various fortification levels in Tomato samples

\begin{tabular}{|c|c|c|c|c|c|c|}
\hline \multirow{2}{*}{$\begin{array}{l}\text { Av.of three } \\
\text { Replications }\end{array}$} & \multicolumn{2}{|c|}{$\begin{array}{c}\text { Profenophos } \\
0.5 \mathrm{mg} / \mathrm{kg}\end{array}$} & \multicolumn{2}{|c|}{$\begin{array}{c}\text { Chlorpyrifos } \\
0.5 \mathrm{mg} / \mathrm{kg}\end{array}$} & \multicolumn{2}{|c|}{$\begin{array}{c}\text { Dimethoate } \\
0.5 \mathrm{mg} / \mathrm{kg}\end{array}$} \\
\hline & $\begin{array}{c}\text { Calculated } \\
\text { Level } \\
(\mathbf{p p m})\end{array}$ & $\begin{array}{c}\% \\
\text { Recovery }\end{array}$ & $\begin{array}{c}\text { Calculated } \\
\text { Level } \\
(\text { ppm) }\end{array}$ & $\begin{array}{c}\% \\
\text { Recovery }\end{array}$ & $\begin{array}{c}\text { Calculated } \\
\text { Level } \\
(\mathrm{ppm})\end{array}$ & $\begin{array}{c}\% \\
\text { Recovery }\end{array}$ \\
\hline Average/ & 0.59 & 119 & 0.48 & 96 & 0.48 & 97 \\
\hline
\end{tabular}

The recovery of Profenophos was $119 \%$, Chlorpyrifos $96 \%$, and Dimethoate was $97 \%$ from the Tomato samples fortified at $0.50 \mathrm{mg} / \mathrm{kg}$

Recoveries of Malathion, Phosalone, Quinalphos at various fortification levels in Tomato samples

\begin{tabular}{|c|c|c|c|c|c|c|}
\hline \multirow[t]{3}{*}{ Replication } & \multicolumn{2}{|c|}{ Malathion } & \multicolumn{2}{|c|}{ Phosalone } & \multicolumn{2}{|c|}{ Quinalphos } \\
\hline & $0.5 \mathrm{n}$ & & $0.5 \mathrm{n}$ & & $0.5 \mathrm{n}$ & \\
\hline & $\begin{array}{l}\text { Calculated } \\
\text { Level (ppm) }\end{array}$ & $\begin{array}{c}\% \\
\text { Recovery }\end{array}$ & $\begin{array}{l}\text { Calculated } \\
\text { Level (ppm) }\end{array}$ & $\begin{array}{c}\% \\
\text { Recovery }\end{array}$ & $\begin{array}{l}\text { Calculated } \\
\text { Level (ppm) }\end{array}$ & $\begin{array}{c}\% \\
\text { Recovery }\end{array}$ \\
\hline Average/ & 0.51 & 103 & 0.57 & 114 & 0.46 & 93 \\
\hline
\end{tabular}

The recovery of Malathion was $103 \%$ from the Tomato samples fortified at $0.50 \mathrm{mg} / \mathrm{kg}$ and it was 114.0\% for Phosalone and $93 \%$ from Quinalphos

Recoveries of Triazophos, Lamda cyhalothrin at various fortification levels in Tomato samples

\begin{tabular}{|c|c|c|c|c|}
\hline \multirow{2}{*}{$\begin{array}{c}\text { AV. Of three } \\
\text { Replications }\end{array}$} & \multicolumn{2}{|c|}{ Triazophos } & \multicolumn{2}{c|}{ Lamda cyhalothrin } \\
\cline { 2 - 5 } & \multicolumn{2}{|c|}{ 0.5 mg/kg } & \multicolumn{2}{c|}{.5 mg/kg } \\
\cline { 2 - 5 } & $\begin{array}{c}\text { Calculated Level } \\
(\mathrm{ppm})\end{array}$ & $\begin{array}{c}\% \\
\text { Recovery }\end{array}$ & $\begin{array}{c}\text { Calculated } \\
\text { Level (ppm) }\end{array}$ & Recovery \\
\hline Average & $\mathbf{0 . 4 9}$ & 99 & 0.48 & 97 \\
\hline
\end{tabular}


The recovery of Triazophos was $99 \%$ from the Tomato samples fortified at $0.50 \mathrm{mg} / \mathrm{kg}$. and the recovery of Lambda cyhalothrin was $97 \%$

\section{RESULTS AND DisCUSSION}

The residues of dimethoate, profenophos, chlorpyrifos, malathion, phosalone, quinalphos, triazophos, $\lambda$-cyhalothrin in tomato samples have got substantial reduction by different house hold processing methods. The reduction percentage and residue levels have been presented in Table 3 .

\begin{tabular}{|c|c|c|c|c|c|c|c|c|}
\hline \multicolumn{8}{|c|}{ Table.2. Pesticide Residues (mg/kg) in Tomato Samples collected at 2 hrs after spray } \\
CONTROL \\
\hline
\end{tabular}

Table3. \% removal of pesticide residues over control

\begin{tabular}{|c|c|c|c|c|c|c|c|c|c|}
\hline Pesticide & \multicolumn{9}{|c|}{ Table-3 \% removal of pesticide residues over control } \\
\cline { 2 - 11 } & $\begin{array}{c}\text { Tap } \\
\text { Water }\end{array}$ & $\begin{array}{c}\text { Lemon } \\
\text { water }\end{array}$ & $\begin{array}{c}2 \% \\
\text { tamarind } \\
\text { solution }\end{array}$ & $\begin{array}{c}2 \% \\
\text { salt } \\
\text { solutio } \\
\mathrm{n}\end{array}$ & $\begin{array}{c}0.1 \% \\
\text { sodium } \\
\text { bicarbo } \\
\text { nate } \\
\text { solutio } \\
\mathrm{n}\end{array}$ & $\begin{array}{c}4 \% \\
\text { Acetic } \\
\text { Acid } \\
\text { solutio } \\
\mathrm{n}\end{array}$ & $\begin{array}{c}\text { BIO } \\
\text { WASH }\end{array}$ & $\begin{array}{c}\text { Cookin } \\
\mathrm{g}\end{array}$ & $\begin{array}{c}\text { Formul } \\
\text { a-I }\end{array}$ \\
\hline Dimethoate & 30.700 & 39.000 & 26.800 & 45.300 & 25.400 & 24.400 & 36.500 & 64.000 & 24.100 \\
\hline $\begin{array}{c}\text { Chlorpyriph } \\
\text { os }\end{array}$ & 35.300 & 41.500 & 24.100 & 43.000 & 21.500 & 14.800 & 42.700 & 45.900 & 25.900 \\
\hline Quinolphos & 45.600 & 49.500 & 34.400 & 52.100 & 34.000 & 28.100 & 48.800 & 39.400 & 35.700 \\
\hline Profenophos & 42.000 & 47.100 & 30.500 & 49.800 & 29.800 & 23.100 & 47.900 & 52.900 & 31.300 \\
\hline Phosalone & 44.100 & 49.900 & 29.500 & 54.000 & 33.600 & 22.400 & 51.300 & 42.000 & 31.800 \\
\hline $\begin{array}{c}\square \text { cyhaloth } \\
\text { rin }\end{array}$ & 40.900 & 45.700 & 26.300 & 47.900 & 30.400 & 12.700 & 52.500 & 48.700 & 27.100 \\
\hline Malathion & 70.300 & 69.900 & 65.300 & 76.500 & 61.300 & 54.200 & 72.500 & 81.400 & 59.100 \\
\hline
\end{tabular}

\subsection{Results:}

In the process of washing under running tap water malathion residues were reduced up to $70.30 \%$, whereas phosalone $44.10 \%$, Quinolphos $45.60 \%$, $\lambda$-cyhalothrin $40.90 \%$, Profenophos $42 \%$., Chlorpyriphos $35.30 \%$, and dimethoate were reduced to $30.70 \%$ By washing the tomato samples under running tap water the residue levels of dimethoate were not degraded much..With the method of direct cooking malathion residues were reduced up to $81.40 \%$, dimethoate $64 \%$, Profenophos $52 \% . \lambda$-cyhalothrin $48.70 \%$, and least reduction was seen in quinolphos $39.40 \%$.

The direct cooking method has shown better effect when compared with Tap water washing. By washing with $2 \%$ s alt water malathion residues reduced by $76.50 \%$, Dimethoate $45.30 \%$, phosalone $54 \%$,quinalphos $52.10 \%$, and the lowest reduction was seen in chlorpyriphos residues with a reduction of $43 \%$

Among all the treatments dipping in $2 \%$ tamarind solution, washing with $0.1 \%$ sodium bicarbonate solution ,4\% acetic acid solution, washing with formula $-\mathrm{I}$ were less effective in reducing the pesticide residues compared to washing with tap water, lemon water, washing methods utilized. Among all the methods utilized Direct cooking and washing with $2 \%$ salt solution were most effective.

\subsection{Discussion}

Pesticides are used indiscriminately and excessively throughout the globe, and these residues remain in the food materials, water, fruits, vegetables (Baptista et al.,2008, Lazic et al., 2009) and in total 
diet. Excessive use of pesticides, their toxic residues has been reported in various environmental commodities (Patel et al., 1999, Lazic et al.,2009). These pesticide residues enter in to the human body by consumption of the pesticide contaminated food which leads to the chronic disorders. Thus the removal of these residues from food commodities utilizing different processing methods is very essential) The different house hold preparations such as washing with tap water,washing with lemon water,dipping in $2 \%$ tamarind solution,cooking, dipping in $2 \%$ salt solution.washing with $4 \%$ acetic acid solution, biowash and washing with formula-Iplay a role in the reduction of pesticide residues (Wasim Aktar et al.),2010).

Thus, based on the results obtained in this study it can be concluded that by processing the tomato with the traditional processing methods if it helps in the removal of pesticide residues below MRL levels, then it is safe for human consumption. The results of earlier workers (Elkins ER. 1980, Dhiman et al., 2006, Kumari B.2008, WasimAktar et al., 2010, Saghir A. et al., 2012.) have shown similar results reducing the pesticide residues from tomato and other vegetables.

\section{REFERENCES}

[1] Baptista GC; Trevisan LRP; Franco AA: Silva RA.( 2008.) Deltamethrin residues applied as different formulations in staked cucumber and the actions of insecticides on pickleworm control. Horticulture Brasileira 26: 321-324.

[2] Dhiman,N., Jyot, G.,\& Bakhshi, A. K. (2006). Decontamination of various insecticides in cauliflower and tomato by different processing methods. Mysore journal of Food Science and Technology, 43(1), 92-95.

[3] Elkins ER. Effect of commercial processing on pesticide residues in selected fruits and vegetables. (1980) J Assoc official Agricul Chemists; 7293: 533-35.

[4] Geisman JR, Gunther FA, Gunthur JD, (1975) Eds. Reduction of pesticide residues in food crops by processing. Residue reviews. Residues of pesticides and other contaminants in the total environment Vol. 54: pp. 43-54.

[5] Handa,S.K.(1992.) Monitoring of pesticide residues in Indian environment. Namrutha publications, Madras.221-234.

[6] http://nhb.gov.in/area-pro/Indian\%20Horticulture\%20(2013) (Indian Horticulture Data Base 2013 of National Horticulture Board, Ministry of Agriculture,Government of India)

[7] Jacob, S., \& Verma, S. (1989). Persistence and decontamination of malathion on cabbage. Indian Journal of Entomology, 51(4): 377-383

[8] Jacob, S., \& Verma, S. (1991). Decontamination of Cabbage treated with quinolphos. Indian Journal of Entomology, 53(2), 286-290.

[9] Jimoh, F.O. and Oladiji A.T. (2005). Preliminary studies on Piliostigma thonningii seeds: Proximate analysis, mioneral composition and phytochemical screening. African J. Biotechnology 4 (12) 1439 - 1442.

[10] Karanth,N. G.K. (2000.)Challenges of limiting pesticide residues on fresh vegetables: The Indian experience. In proceedings of the International workshop, CIRAD-FAO, 11-13 December Montepellier, France.

[11] Kumari B, Kumar R, Madan VK, Rajvir S, Jagdeep S, Kathpal TS (2003). Magnitude of pesticidal contamination in winter vegetables from Hisar, Haryana. Environ Monit Assess 87: 311-18.

[12] Kumari B, Madan VK, Kumar R, Kathpal TS.(2002) Monitoring of seasonal vegetables for pesticide residues. Environ Monit Assess ; 74: 263-70.

[13] Kumari B. Effects of household processing on reduction of pesticide residues in vegetables. (2008) J agricul Biol Sci 2008; 3(4): 1990-45.

[14] Md.WasimAkthar. Dwaipayan Seengupta. Swarnali Purkait. Ashim Cowdhury. (2010). Risk assessment and decontamination of Quinolphos under different culinary processes in on cabbage.Environ Monit Assess 163:369-377.

[15] Nagesh, M., \& Verma, S. (1997). Decontamination of cabbage treated with chlorpyriphos and quinolphos. Indian Journal of Entomology, 5994), 404-410.

[16] Patel, B.A., Shah, Mf., Patel, j.L., \& Talati, J. G. (1999). Chlorpyriphos residues in/on cabbage 
and tomato. Pesticide Research Journal, 11(2), 194-196.

[17] Ramesh, A., Balasubramanian, M., ramesh, A., \& Balasubramanian,M. (1999). The impact of household preparation in the residues of pesticides in selected agricultural commodies available in india. Journal of AOAC International, 82(3), 725-737.

[18] S.D. Lazic, V.P. Bursic, S.M. Vukovic, D.B. Sunjka, M.M. Pucarevic, (2009), Pesticide Residues in Vegetable Samples from the Market of the Republic of Serbia during 2007, Acta Horticulturae No: 830

[19] Saghir A. Sheikh, Shafi M. Nizamani, Asif A. Jamail, Aasia A. Panhwar, Mahvish J. Channa and Beenish N. Mirani,( 2012), Journal of Basic \& Applied Sciences, 8: 79-84.

[20] Sardana HR. ( 2001) Integrated pest management in vegetables. In: Traning manual-2, Training on IPM for Zonal Agricultural Research Station; 21-26,May. Pp. 105-118.

[21] Srinivastava LP, Buuhar R, Raizada RB. (2001) Organochlorine pesticide residues in Indian spices. Bull Environ Contamination Toxicol 856- 62.

[22] Srinivastava LP, Gupta KP, Raizada RB. (2000) Organochlorine pesticide residues in herbal preparation. Bull Environ Contaminat Toxicol 64: 502-7.

[23] Srinivastava LP, Kumar N, Gupta KP, Raizada RB. (2006) Status of HCH residues in Indian medicinal plant materials. Bull Environ Contaminat Toxicol 76: 782-90.

[24] Sumitra Arora, and D.K.Singh,(20040 Determination of Chlorpyriphos and Cypermethrin Residues in/on okra. Pesti. Res. J., 16(2), 2004, 68-70.

[25] Torres RL, Torres ILS, Gamaro GD, Fontella FU, Silveira PP, Moreira JSR.(2004) Lipid peroxidation and total radical-trapping potential of the lungs of rats submitted to chronic and subchronic stress. Brazil J Med Biol Res 37: 185-92.

[26] Wang L, Yongchao L, Xin J (2008) . Analysis of eight organphosphorus pesticide residues in fresh vegetables retailed in agricultural product market of Nanjing, China. Bull Environ Contaminat Toxicol 81: 377-82. 